\title{
Coupling meteorological variables with Moderate Resolution Imaging Spectroradiometer atmospheric products for estimating global solar radiation
}

\section{Article}

Accepted Version

Creative Commons: Attribution-Noncommercial-No Derivative Works 4.0

Chen, J.-L., He, L., Yang, H., Chen, Q., Mao, M.-H., Wang, X.X. and Xiao, Z.-L. (2020) Coupling meteorological variables with Moderate Resolution Imaging Spectroradiometer atmospheric products for estimating global solar radiation. Energy Conversion and Management, 205. 112383. ISSN 0196-8904 doi:

https://doi.org/10.1016/j.enconman.2019.112383 Available at https://centaur.reading.ac.uk/88506/

It is advisable to refer to the publisher's version if you intend to cite from the work. See Guidance on citing.

To link to this article DOI: http://dx.doi.org/10.1016/j.enconman.2019.112383

Publisher: Elsevier

All outputs in CentAUR are protected by Intellectual Property Rights law, including copyright law. Copyright and IPR is retained by the creators or other copyright holders. Terms and conditions for use of this material are defined in the End User Agreement. 


\section{www.reading.ac.uk/centaur}

\section{CentAUR}

Central Archive at the University of Reading

Reading's research outputs online 
1 Coupling meteorological variables with Moderate Resolution Imaging

2 Spectroradiometer atmospheric products for estimating global solar

3 radiation

4

5

6

7

${ }^{a}$ Key Laboratory on Water Environment of Reservoir Watershed, Chongqing Institute of Green and 9

Ji-Long Chen ${ }^{\text {a }}$, L He ${ }^{\text {b }}$, Hong Yang ${ }^{c, d}$, Qiao Chen a , Maohua Ma a , Xiao-Xiao Wang ${ }^{\text {a }}$, Zuo-lin Xiao e**

Intelligent Technology, Chinese Academy of Sciences, Chongqing 401122, China

${ }^{\mathrm{b}}$ Key Laboratory of Poyang Lake Wetland and Watershed Research, Ministry of Education, Nanchang 330000, China

${ }^{\mathrm{c}}$ Collaborative Innovation Center of Atmospheric Environment and Equipment Technology, Jiangsu Key Laboratory of Atmospheric Environment Monitoring and Pollution Control (AEMPC), School of Environmental Science and Engineering, Nanjing University of Information Science \& Technology, Nanjing 210044, China

d Department of Geography and Environmental Science, University of Reading, Reading, Whiteknights, RG6 6AB, UK

${ }^{\mathrm{e}}$ The Key Laboratory of GIS Application Research, Chongqing Normal University, Chongqing 401331, China

*Corresponding author:

Dr. Zuo-lin Xiao

The Key Laboratory of GIS Application Research 
Chongqing Normal University, Chongqing 401331, China

Tel.: +8602365935878

Email address: xiaoll@cqnu.edu.cn

Abstract: Global solar radiation is a crucial variable for scientific researches and solar energy application, while it is measured at very few sites mainly due to the technical and fiscal obstacles. Developing robust and accurate models for estimating global solar radiation had been being a focus for many studies. This study was conducted to develop integrated models combining Moderate Resolution Imaging Spectroradiometer atmospheric products and meteorological variables. 43 empirical models based on the meteorological variables were collected. A total of 645 integrated models incorporating atmospheric constituents into the empirical models were developed. The researched models were evaluated and compared at Chongqing in Three Gorges Reservoir Area, China. The results showed that the integrated models outperformed the empirical models. The best integrated model had the root mean square error of $0.817 \mathrm{MJ} \mathrm{m}^{-2}$ and relative root mean square error of $8.11 \%$. On average, the integrated models had the root mean square error of $1.071 \mathrm{MJ} \mathrm{m}^{-2}, 15.6 \%$ smaller than the empirical models. The results suggest that coupling Moderate Resolution Imaging Spectroradiometer atmospheric products with meteorological variables can enhance the performance of the conventional empirical models, which may provide a promising alternative to generate global solar radiation data with better accuracy.

Keywords: Global solar radiation, Moderate Resolution Imaging Spectroradiometer, empirical models, meteorological variables 


\section{Introduction}

Solar radiation arriving at the earth's surface plays an important role in maintaining physical [1], biological [2] and chemical processes on the earth [3]. It is an essential variable for scientific researches in climate [4], ecology [5] and agriculture [6], as well as a crucial parameter for engineering applications in designing solar furnaces [7], sizing photovoltaic cells [8] and developing efficient solar energy system [9]. However, solar radiation data are not easily available mainly due to the equipment [10], measuring manipulation [11] and financial limitations [12]. As the result, great efforts have been made to estimate global solar radiation from other commonly measured meteorological variables such as air temperature [13] and sunshine duration [14]. Due to the simplicity and operability yet reasonable accuracy, empirical model is the most widely employed approach [15].

Many empirical models have been developed in literatures among which the earliest ones were proposed by Angstrom [16] and Prescott [17]. They correlated clearness index (ratio of global solar radiation to extraterrestrial radiation) with sunshine fraction (the ratio of sunshine duration to potential sunshine duration) and developed the Angstrom-Prescott (A-P) model. This model was revised by many researchers. For example, Almorox and Hontoria [18] developed an exponential model for Spain; Ampratwum and Dorvlo [19] proposed a logarithmic equation for arid region in Oman; Ogelman et al. [20] suggested a quadratic function for Turkey. Bahel et al. [21] proposed a cubic model based on the data of 48 stations around the world. Newland [22] modified the A-P model and proposed a linear logarithmic model. However, many comparative studies suggested that those revisions did not improve the estimation. For example, Chen et al. [23] evaluated the accuracy of 28 sunshine-based models and reported that revision of the A-P model by changing the structure from linear to nonlinear were generally ineffective. Yorukoglu and Celik [24] investigated the performances of linear, quadratic, cubic, logarithmic and exponential models, and the results showed that those models returned similar error 
indicators at Ankara in Turkey. Zhou et al. [25] assessed the precision of several sunshine-based models and found that the A-P model performed similarly to its revisions in China. Consequently, air temperature [26], relatively humidity [27], precipitation [28], atmospheric pressure and vapor pressure [29] were incorporated. Comparisons and evaluations showed that these modifications enhanced the accuracy of the A-P models. Chen and Li [30] calibrated 9 sunshine-based models and the comparisons showed that the modification to A-P model by introducing air temperature decreased the estimation error of the A-P model. Falayi et al. [31] observed that the combination of sunshine duration, temperature and relative humidity yielded better precision than other models in Nigeria. Ouali and Alkama [32] evaluated the performances of 4 models and reported that inclusion of precipitation and wind velocity increased the accuracy of the models employing sunshine fraction in Nigeria.

The sunshine-based models were widely used because of their promising performances. However, they are limited to the sites with available sunshine data [33]. Therefore, Hargreaves and Samani [34] proposed a simple function (H-S model) of air temperature. Bristow and Campbell [35] also developed an exponential model (B-C model) using temperature range. Both models were widely modified and validated, and the evaluations showed that the performances of $\mathrm{H}-\mathrm{S}$ and $\mathrm{B}-\mathrm{C}$ models and their modifications varied from regions to regions, and the accuracies were affected by the geographic location and local climate [36]. For example, Hunt et al. [37] introduced precipitation in an additive form that significantly outperformed the H-S model at 8 sites in Canada. Thornton and Running [38] modified the B-C model and presented a new formulation using temperature, relative humidity and atmospheric pressure. Evaluation showed that the new model outperformed that B-C model at 40 stations in the USA, while this new model gave similar estimation to the H-S model in North America [39].

Although great efforts have been conducted and a large number of empirical models had been 
developed since the pioneering works of Angstrom [16] and Prescott [17]. It is still difficult to develop more robust and accuracy models due to the complex process of radiation [40]. Evaluations and comparative studies indicated that empirical models employing the meteorological variables have overreached their predictive limits [41]. Besides, the empirical models based on meteorological measurements at point scale are insufficient for the application at regional scale [42], particularly for the large, remote areas where measurements of climatological variables are difficult [43].

Solar radiation is attenuated mainly by cloud, aerosol, and water vapor on its way through the atmosphere [42]. The impact of cloud on solar radiation is more pronounced than those by other atmospheric constituents [44]. Because a large part of radiation is reflected back to space by cloud, beam radiation can decrease to a level at $0 \mathrm{MJ} \mathrm{m}^{-2}$ [45]. Aerosol mainly scatters shortwave radiation in forward direction [46]. Water vapor contributes little in absorbing near-infrared radiation but significantly in budgeting the heat in the lower atmosphere [47]. These atmospheric constituents can be detected at large spatial and temporal scales with satellite observation, which overcomes the limitations of site measurements and provides an opportunity to enhance the performances of the empirical models by incorporating satellite observation with ground measurements of climatological variables.

MODIS (Moderate Resolution Imaging Spectroradiometer) is a key sensor operated on both the Terra and Aqua satellites. Its detectors can measure 36 spectral bands between 0.41 and $14.39 \mu \mathrm{m}$ [42]. Many products derived from MODIS observations deliver featured information that can be used for studies of global dynamics and processes involving in land, oceans, and the lower atmosphere. Among these products, MODIS aerosol products (MOD04) monitor the properties of the aerosol over land and ocean surfaces [48]; MODIS precipitable water product (MOD05) consists of column water-vapor amounts [49]; MODIS cloud product (MOD06) combines infrared emission and solar reflectance techniques for determining both physical and radiative cloud properties [50]. These datasets played an important role in 
understanding of atmosphere dynamics and the land-atmosphere interactions. Moreover, MODIS products are widely available for free.

Thus, estimations of solar radiation employing the MODIS data have recently been investigated. Performances of four machine learning algorithms integrated with MODIS datasets were evaluated in Australia [51], showing that those algorithms integrated with MODIS data can be applied as a qualified tool in data-sparse regions. After investigating the precision of artificial neural network using MODIS data in Queensland, Ravinesh and Mehmet [52] confirmed that this algorithm coupled with MODIS data was a powerful stratagem. The random forest approach using MODIS data was applied in the USA [53], indicating that the model simulations matched well with the observations. A comparative study of four models was conducted in China [54], and results showed that those models with MODIS data can be used to reveal the spatial-temporal variations of solar radiation at large scale. Considering atmosphere as homogeneous and plane-parallel layers without three-dimensional effects, Chen et al. [55] developed a computing scheme using MODIS atmospheric products based on radiative transfer processes. Although evaluations showed good agreement between the estimations and observations, the rigorous radiative transfer algorithms are too complicated, data-intensive and time-consuming to be handled by users in other areas. Therefore, a simple model with reasonable accuracy using MODIS atmospheric products across China was proposed by Chen et al. [42].

Due to the optimum trade-off between simplicity and accuracy, empirical model employing the meteorological variables is the most common approach for estimating solar radiation at point scale. Recent studies suggested that MODIS data can be used to obtain solar radiation data, particularly for the data sparse and remote areas. Moreover, it can be used to retrieve the spatial distribution of radiation at large scale. It is therefore open to question whether and to what extent the performance of the empirical model can be enhanced by combining the meteorological variables with MODIS atmospheric products. 
With respect to the advantages of MODIS data and the empirical approach, estimation of global solar

radiation coupling MODIS data with meteorological variables was investigated in this study. The main objectives of this study are to (1) collect the widely used empirical models employing different combinations of meteorological variables, (2) develop integrated empirical models by coupling meteorological variables with MODIS atmospheric products, and (3) evaluate and compare the presently developed models against the empirical models in the Three Gorges Reservoir Area (TGRA), China.

2 Materials and methods

This section provides the details about the collected empirical models, the process of the integrated models developments, the evaluation and validation indicators, the research site, data collection and processing of MODIS atmospheric products and meteorological datasets.

\subsection{Empirical models}

In order to verify the performances of the newly developed models, a total of 43 widely used empirical models employing different combinations of meteorological variables were collected and evaluated. Among them, 25 models (models 1-25) were reported for the sunshine-based models, and 18 models (models 26-43) for the temperature-based models.

Model 1: Angstrom [16] developed a simple correlation between the ratio of global radiation to the radiation on a clear day and sunshine fraction. Replacing the radiation on a clear day with the extraterrestrial radiation, Prescott [17] revised the Angstrom model and proposed the following model:

$$
\text { Model 1: } R s / R a=a S / S o+b
$$

where $a$ and $b$ are empirical coefficients; $S$ is sunshine duration; $S o$ is potential sunshine duration; $R S$ is global solar radiation; $R a$ is extraterrestrial radiation. $R s$ and $R a$ are calculated using the equations detailed by Allen et al [64].

$$
R a=37.6 d(\omega \sin \sin \delta+\cos \cos \delta \sin \omega)
$$




$$
d=1+0.033 \cos \left(\frac{2 \pi}{365} n\right)
$$

$$
\delta=0.4093 \sin \left(\frac{2 \pi}{365} n-1.39\right)
$$

$$
\omega=\arccos (-\tan \varphi \tan \delta)
$$

$$
S o=24 \omega / \pi
$$

where $\mathrm{d}$ is the relative distance between the sun and the earth; $\omega$ is sunset hour angle (rad); $\varphi$ is latitude ( $\mathrm{rad}) ; \delta$ is solar declination angle $(\mathrm{rad}) ; \mathrm{n}$ is the number of the day of year starting from the first of January.

$$
\text { Model 2: } R s / R a=a+b_{1} S / S_{0}+b_{2} \exp \left(S / S_{0}\right)
$$

Model 3: Newland [22] added a logarithmic term to the A-P model and presented a linear logarithmic model.

$$
\text { Model 3: } R s / R a=a+b_{1} S / S_{0}+b_{2} \log \left(S_{/} S_{0}\right)
$$

Model 4: Ögelman et al. [20] proposed a quadratic model using sunshine fraction in the following form:

$$
\text { Model 4: } R s / R a=a+b_{1} S / S_{0}+b_{2}\left(S / S_{0}\right)^{2}
$$

Model 5: Bahel et al. [21] developed a cubic function of sunshine fraction.

$$
\text { Model 5: } R S / R a=a+b_{1} S / S_{0}+b_{2} S / S_{0}^{2}+b_{3} S / S_{0}^{3}
$$

Models 6-7: Falayi et al. [31] introduced temperature to modify the A-P model and reported the following models:

$$
\begin{aligned}
& \text { Model 6: } R s / R a=a+b_{1} S / S_{0}+c_{1} T \\
& \text { Model 7: } R s / R a=a+b_{1} S / S_{0}+c_{1} T m i n
\end{aligned}
$$

where $T$, Tmin is average temperature and minimum air temperature, respectively; $c_{1}$ is empirical 
coefficient.

Model 8: Olayinka [58] suggested the following model using sunshine fraction and maximum temperature:

$$
\text { Model 8: } R s / R a=a+b_{1} S / S_{0}+c_{1} T \operatorname{Tmax}
$$

where Tmax is maximum air temperature.

Models 9-13: Chen and Li [30] developed the following multivariate linear models combing sunshine fraction, minimum temperature, maximum temperature, precipitation, atmospheric pressure and relative humidity.

$$
\text { Model 9: } R s / R a=a+b_{1} S / S_{0}+c_{1} \operatorname{Tmin}+c_{2} \operatorname{Tmax}
$$

$$
\text { Model 10: } R s / R a=a+b_{1} S / S_{0}+e_{1} P
$$

$$
\text { Model 11: } R s / R a=a+b_{1} S / S_{0}+f_{1} A p
$$

$$
\text { Model 12: } R s / R a=a+b_{1} S / S_{0}+c_{1} T \min +c_{2} \operatorname{Tmax}+d_{1} R h
$$

$$
\text { Model 13: Rs } / R a=a+b_{1} S / S_{0}+c_{1} T \operatorname{Tin}+c_{2} T \operatorname{Tmax}+e_{1} P
$$

where $P, A p$ and $R h$ are precipitation, atmospheric pressure and relative humidity, respectively; $d_{1}, e_{1}$ and $f_{l}$ are empirical coefficients.

Models 14-16: Abdallah [59] presented the following models employing sunshine fraction, temperature range, average temperature and relative humidity.

$$
\text { Model 14: } R s / R a=a+b_{1} S / S_{0}+c_{1} \Delta T
$$

Model 15: $R s / R a=a+b_{1} S / S_{0}+c_{1} T+d_{1} R h$

$$
\text { Model 16: } R s / R a=a+b_{1} S / S_{0}+c_{1} \Delta T+d_{1} R h
$$

where $\Delta T$ is air temperature range.

Model 17: Swartman and Ogunlade [60] modified the A-P model using relative humidity and proposed the following model: 
Model 18: Bakirci [28] developed a new model employing sunshine fraction and relative humidity.

$$
\text { Model 18: } R s / R a=a+b_{1} S / S_{0}+b_{2}\left(S / S_{0}\right)^{2}+d_{1} R h
$$

maximum temperature and relative humidity.

$$
\text { Model 19: } R s / R a=a+b_{1} S / S_{0}+c_{1} T \operatorname{Tmax}+d_{1} R h
$$

Model 20: Chen et al. [62] modified the A-P model using average temperature and precipitation and proposed the following model:

$$
\text { Model 20: } R s / R a=a+b_{1} S / S_{0}+c_{1} T+e_{1} P
$$

Model 22: Kirmani et al. [64] reported a multivariate linear model employing sunshine fraction, average temperature, relative humidity and precipitation in the following form:

$$
\text { Model 22: } R s / R a=a+b_{1} S / S_{0}+c_{1} T+d_{1} R h+e_{1} P
$$

Model 23: Chen and $\mathrm{Li}$ [65] coupled the sunshine fraction with air temperature range, relative humidity and atmospheric pressure and developed a new model as follow.

$$
\text { Model 23: } R s / R a=a+b_{1} S / S_{0}+c_{1} \Delta T^{0.5}+d_{1} R h+f_{2} A p
$$

Model 24: Adeala et al. [66] suggested the following function of sunshine fraction, temperature range, relative humidity and wind velocity.

$$
\text { Model 24: } R s / R a=a+b_{1} S / S_{0}+c_{1} T+d_{1} R h+h_{1} W v
$$

where $W v$ is wind velocity, and $h_{1}$ is empirical coefficient.

Model 25: Ouali and Alkama [67] presented a multivariate linear model incorporating sunshine 
fraction, average temperature, relative humidity, precipitation and wind velocity.

Model 26: Hargreaves and Samani [34] suggested a simple model using the temperature range.

$$
\text { Model 26: } R s / R a=a+c_{1}(\Delta T)^{0.5}
$$

Models 27-28: Falayi et al. [31] developed 2 simple models employing the average temperature and minimum temperature.

$$
\begin{aligned}
& \text { Model 27: } R s / R a=a+c_{1} T \\
& \text { Model 28: } R s / R a=a+c_{1} \text { Tmin }
\end{aligned}
$$

Model 29: Awachie and Okeke [68] presented a linear correlation between clearness index and maximum temperature:

$$
\text { Model 29: } R s / R a=a+c_{1} \text { Tmax }
$$

Model 30: Bristow and Campbell [35] proposed an exponential function of temperature range.

$$
\text { Model 30: } R s / R a=c_{1}\left(1-\exp \left(c_{2} \Delta T^{c 3}\right)\right)
$$

Models 31-32: Ohunakin et al. [69] reported the following models using temperature range and average temperature:

$$
\begin{gathered}
\text { Model 31: } R s / R a=a+c_{1}(\Delta T)^{0.5}+c_{2}(\Delta T) \\
\text { Model 32: } R s / R a=a+c_{1} T+c_{2} T^{2}
\end{gathered}
$$

Models 33-34: Li et al. [70] developed 2 linear models combing maximum temperature, minimum temperature and precipitation:

$$
\begin{gathered}
\text { Model 33: } R s / R a=a+c_{1} \text { Tmax }+c_{2} \text { Tmin } \\
\text { Model 34: } R s / R a=a+c_{1} \text { Tmax }+c_{2} \text { Tmin }+e_{1} P
\end{gathered}
$$

Models 35-36: Okundamiya and Nzeako [71] suggested 2 quadratic models employing minimum temperature and maximum temperature. 
Model 37: El-Sebaii et al. [72] reported a new model combing average temperature and relative humidity.

Models 38-42: Chen and $\mathrm{Li}$ [30] developed 5 models coupling air temperature with relative RS5-10 employed the possible combinations of two variables, models RS11-14 incorporated three variables of atmospheric constituent, and model RS 15 used all the selected atmospheric constituent

$$
\text { Model 38: } R s / R a=a+c_{1} \Delta T^{0.5}+d_{1} R h
$$

$$
\text { Model 39: } R s / R a=a+c_{1} \Delta T^{0.5}+e_{1} P
$$

$$
\text { Model 40: } R s / R a=a+c_{1} \Delta T^{0.5}+f_{1} A p
$$

$$
\text { Model 41: } R s / R a=a+c_{1} \Delta T^{0.5}+d_{1} R h+f_{1} A p
$$

$$
\text { Model 42: } R s / R a=a+c_{1} \operatorname{Tmax}+c_{2} \operatorname{Tmin}+d_{1} R h+f_{1} A p
$$

Model 43: Korachagaon and Bapat [73] suggested the following model using maximum temperature, temperature range and relative humidity.

$$
\text { Model 43: } R s / R a=a+c_{1} T \max +c_{2} \Delta T+d_{1} R h
$$

\subsection{New model development}

After a number of preliminary experimental investigations, a total of 15 models using the possible combinations of cloud fraction, cloud optical thickness, aerosol optical thickness and precipitable water vapor amount were developed (Table 1). These parameters were widely employed for satellite-based retrieval of solar irradiance [74]. Among these models, models RS1-4 used one variable only, models variables. 

empirical models were further developed. The possible combinations of 43 empirical models and 15 new models resulted in $645(43 \times 15)$ coupled models by incorporating the linear combination of atmospheric constituents into the empirical models in additive form. For example, integrating model RS15 into model 1 resulted in model M1RS15 as the following form:

$$
\mathrm{Rs} / \mathrm{Ra}=\mathrm{a}+\mathrm{b}_{1} \mathrm{~S} / \mathrm{S}_{0}+\mathrm{a}_{1} \mathrm{CF}+\mathrm{a}_{2} \mathrm{COT}+\mathrm{a}_{3} \mathrm{PWV}+\mathrm{a}_{4} \mathrm{AOT}
$$
where $\mathrm{CF}$, COT, PWV and AOT are cloud fraction, cloud optical thickness, precipitable water vapor amount and aerosol optical thickness, respectively. The part of $\mathrm{b}_{1} \mathrm{~S}_{/} \mathrm{S}_{0}$ is from the model 1 , and the part of $\mathrm{a}_{1} \mathrm{CF}+\mathrm{a}_{2} \mathrm{COT}+\mathrm{a}_{3} \mathrm{PWV}+\mathrm{a}_{4} \mathrm{AOT}$ is from model RS15. Other models were developed as the same way and presented in Table 2 .

\subsection{Statistical evaluation and validation}

Root mean square error (RMSE) and relative root mean square error (RRMSE) (\%) were selected to assess the researched models. RMSE is a widely used indicator for evaluating the model performances by allowing a term-by-term comparison of the estimation and measurements. RRMSE is a relative error indicator allowing comparisons among a range of different models. Lower RMSE and RRMSE mean better performances. RMSE and RRMSE were calculated using the following equations:

$$
R M S E=\sqrt{\frac{\sum_{i=1}^{n}\left(y_{i, m}-y_{i, p}\right)^{2}}{n}}
$$

(50) $\operatorname{RRMSE}(\%)=100 \sqrt{\frac{\sum_{i=1}^{n}\left(y_{i, m}-y_{i, p}\right)^{2}}{n y_{i, m}}}$ where $n, y_{i, m}$, and $y_{i, p}$ are the number of validating record, the measurements and the estimations, respectively.

\subsection{Research site}

The researched models were evaluated and compared at the Chongqing meteorological station in the upper section of TGRA in China $\left(29^{\circ} 35^{\prime} \mathrm{N}, 106^{\circ} 28^{\prime} \mathrm{E}\right)$, with the elevation of $259.1 \mathrm{~m}$ above the sea 
level. Chongqing is in the subtropical monsoon climate zone with a hot and humid summer and a cool winter [75]. Figure 1 shows the temporal variation of meteorological variables at the research site. Monthly sunshine duration ranged from the maximum in July to the minimum in December, with the average of $2.73 \mathrm{~h}$ (Fig.1a). Monthly precipitation ranged from the maximum in June and the minimum in

December, with the annul amount of $1099 \mathrm{~mm}$ (Fig.1a). Maximum, average and minimum temperatures presented the similar temporal variations with the highest peak in July and lowest in January (Fig.1b). 
the World Meteorological Organization (WMO) [40]. The assumed homogeneity was also implied by a similar trend of the Chinese radiation data series [79] to those from other places [80]. Sunshine duration (h), air temperatures $\left({ }^{\circ} \mathrm{C}\right)$, atmospheric pressure (Kpa), and relative humidity $(\%)$ were measured using Jordan sunshine recorder, Mercury alcohol thermometers, Mercury barometer, and Aspirated psychomotor at $2 \mathrm{~m}$ height, respectively [40]. Wind velocity $(\mathrm{m} / \mathrm{s})$ was measured using EL wind electric anemometer at $10 \mathrm{~m}$ height, which was transformed to speed at $2 \mathrm{~m}$ height by the method proposed by FAO56 [56]. All the equipment and sensors were checked and calibrated periodically, and all the measurements were made following the procedures recommended by the WMO [79].

\subsection{Data check and processing}

Although the quality of meteorological data has been checked by the NMIC. Meteorological records probably still contain errors associated with the manipulations, sensors errors and occasional voltage instability [81]. Therefore, the quality control scheme suggested by Feng et al. [82] and Tang et al. [83] was adopted to further check the data. Firstly, the records with missing data labeled by the feature values were removed. Secondly, the data with evident systematic errors were removed. Finally, a multivariate regression relationship between global radiation and meteorological variables was built to exclude noisy data and suspected data. More details can be referred to Feng et al. [82] and Tang et al. [83]. For the MODIS atmospheric constituent dataset, the records with missing value filled by 9999 were excluded from the dataset.

Each record of atmospheric constituents and meteorological data was identified uniquely by the year and month. Thus, an integrated dataset combining the meteorological data with the corresponding atmospheric constituent data was subsequently built by the unique identification. The records with missing data of atmospheric constituent data or meteorological data were further removed. Then two sub-datasets were built; the first $75 \%$ of the records were used for modelling and calibration, and the 
remaining $25 \%$ for evaluation and validation.

3. Results and discussion

The performances of the researched models were presented in Table 1 and Tables 3-5. The calibrated coefficients of the models were presented in supplementary data. All the collected empirical models (models 1-43) performed well with the average RMSE of $1.269 \mathrm{MJ} \mathrm{m}^{-2}$ and the average RRMSE of 12.58\%. Model 25 was the most accurate one with the lowest RMSE of $0.967 \mathrm{MJ} \mathrm{m}^{-2}$ and the RRMSE of $9.58 \%$, while the error indicators were similar to models 12, 13, 15, 22 and 24. Overall, the sunshine-based models (models 1-25) had the average RMSE of $1.051 \mathrm{MJ} \mathrm{m}^{-2}$ and the average RRMSE of $10.41 \%$, which were lower than $1.574 \mathrm{MJ} \mathrm{m}^{-2}$ and $15.61 \%$, respectively, for the temperature-based models (models 26-43), suggesting that the sunshine-based models were superior to the temperature-based models. This confirmed the results of previous studies. For example, Chen et al. [23] evaluated the performances of 273 sunshine-based and temperature-based models and the results suggested that the sunshine-based models are generally more accurate than the temperature-based models in China. Besharat et al [84] comprehensively reviewed 78 empirical models, and the evaluation showed that the sunshine-based models outperformed the temperature-based models in Iran.

Models 2-5 are the revisions of the A-P model by changing the structure from linear to nonlinear forms. Models 1-5 had very similar estimations, indicating that such revisions by changing the structure from linear to nonlinear were generally ineffective and yielded little improvement. This agreed well with previous conclusions from Yorukoglu and Celik [24], Zhou et al. [25] and Chen et al [6] who investigated and compared the performances of sunshine-based models, and reported that the revised versions of A-P model, including the linear exponential, linger logarithm, quadratic and cubic models, performed similar to the A-P model. Only a few works reported better performances. For instance, Bakirci [28] evaluated some sunshine duration models and observed that the linear exponential 
performed best in different regions of Turkey. Newland [22] found that the linear logarithmic function showed better estimation than the A-P model in South China.

enhanced the performances of the sunshine duration models. This was further proved by the better performances of models 12, 15, 16 and 19 than the model 17, and lower estimation errors of models 13 , 20 and 21 than the model 10. The results were consistent with those from Khil-Ha Lee [26], Chen et al. 
improvement in estimating accuracy of the A-P model.

When sunshine duration data were unavailable, the temperature-based models (models 26-43)

generated reasonable estimations with the average RMSE of $1.574 \mathrm{MJ} \mathrm{m}^{-2}$ and average RRMSE of 15.61\%. Model 42 gave the best estimation with the lowest RMSE of $1.154 \mathrm{MJ} \mathrm{m}^{-2}$ and the RRMSE of $11.44 \%$, followed by model 43 with similar error indicators to model 42 .

Models $27-29,32,35$ and 36 only using average or maximum or minimum temperature had the average RMSE of $1.875 \mathrm{MJ} \mathrm{m}^{-2}$ and average RRMSE of $18.59 \%$, which were relatively higher than other temperature-based models. The poor performances of these models had also been reported by Chen et al. [89] who claimed that the models using temperature only were unsuitable for estimating solar radiation in China. The average RMSE and RRMSE decreased to $1.519 \mathrm{MJ} \mathrm{m}^{-2}$ and $15.07 \%$, respectively, for models 26, 30, 31 and 33 which used the combination of maximum and minimum temperatures. The B-C model (model 30) and model 31 had similar estimations, which were slight better than the H-S model (model 26).

Model 37 using relative humidity and average temperature showed much lower RMSE and RRMSE than model 27, suggesting that inclusion of relative humidity increased the estimating accuracy of the models only using air temperature. This was further confirmed by the better performances of models 38 and 43 over the corresponding models 27 and 29.

Model 40 using atmospheric pressure and temperature range outperformed model 26, suggesting that modifications to the H-S models by introducing atmospheric pressure can enhance its performance. This was also indicated by the lower estimation errors of model 41 than model 38 . These results agreed well with the findings of Chen and $\mathrm{Li}[30]$ who founded the additional inclusion of atmospheric pressure and relative humidity decreased the estimating errors of the temperature models. Model 39 performed similarly to the H-S model, indicating that inclusion of the precipitation as an additive form hardly 
improved its accuracy, whereas Ouali and Alkama [67] discovered that the application of precipitation

414 enhanced the performance of temperature models in Algeria.

415 Among the models (models RS1-15) using atmospheric constituents, model RS15 using all the 416 atmospheric constituents had the lowest RMSE of $1.267 \mathrm{MJ} \mathrm{m}^{-2}$ and the lowest RRMSE of $12.56 \%$,

417 which were very similar to the corresponding values of $1.269 \mathrm{MJ} \mathrm{m}^{-2}$ and $12.58 \%$ for the model RS12 418 using cloud fraction, cloud optical thickness and precipitable water vapor amount. Models RS2-4, 8 and 41910 showed higher estimating errors than other modes. It was generally recognized that cloud cover was 420 the most important factor attenuating solar radiation [42]. However, the model RS1 only using cloud 421 fraction explained $61 \%$ of the solar radiation variance (supplement data). The result confirmed the 422 previous finding that dependence of global solar radiation on cloud was not entirely deterministic [90].

423 The estimation errors of models RS5 and RS7 were much lower than model RS1, suggesting that 424 inclusion of cloud optical thickness and precipitable water vapor amount markedly increased the 425 estimating accuracy of the models only using cloud fraction. This was also proved by the better 426 performances of models RS 11-13 than model RS1. While model RS6 generated similar estimation with 427 model RS1, generally implying that aerosol optical thickness did not contribute to the improvement in 428 estimating accuracy. The results confirmed the previous findings over China [42].

429 All the integrated models combining the meteorological variables and atmospheric constituents 430 showed good performances with the average RMSE of 1.071 $\mathrm{MJ} \mathrm{m}^{-2}$ and the RRMSE of $10.62 \%$, which 431 were lower than the corresponding values of $1.269 \mathrm{MJ} \mathrm{m}^{-2}$ and $12.58 \%$ for the empirical models $1-43$, 432 suggesting that incorporation of atmospheric constituents enhanced the performance of empirical models 433 employing meteorological variables. The models $\left(16^{\text {th }}\right.$ column in Tale 2 and Table 4-5) using the 434 meteorological variables and all the atmospheric constituents had the lowest average RMSE of 0.929 MJ $435 \mathrm{~m}^{-2}$ and the RRMSE of $9.22 \%$ and they performed similarly to the models $\left(13^{\text {th }}\right.$ column Tale 2 and Table 
4-5) using the meteorological variables and cloud fraction, cloud optical thickness and precipitable water

vapor amount. Amongst all the integrated models, the model M25RS15 performed best with the lowest RMSE of $0.817 \mathrm{MJ} \mathrm{m}^{-2}$ and the RRMSE of $8.11 \%$.

Models M1RS2-M25RS2 had the average RMSE of $0.938 \mathrm{MJ} \mathrm{m}^{-2}$, which was $10.63 \%$ lower than the models 1-25, suggesting that incorporation of cloud optical thickness into the sunshine-based models improved their estimations. The average RMSE of models M1RS1-M25RS1, M1RS3-M25RS3, and M1RS4-M25RS4 were 1.016 $\mathrm{MJ} \mathrm{m}^{-2}, 1.045 \mathrm{MJ} \mathrm{m}^{-2}$, and $1.017 \mathrm{MJ} \mathrm{m}^{-2}$, respectively, which were very similar to $1.051 \mathrm{MJ} \mathrm{m}^{-2}$ for models $1-25$. This implied that additional inclusions of cloud fraction, aerosol optical depth, and precipitable water vapor amount to the sunshine-based models yielded little improvement. The reason for lack of improvement may be that the potential effects of those additional variables had already been implicitly reflected in the sunshine-based models. The other reason may lie in the inter-dependency of different variables [6].

Models M1RS5-M25RS5, M1RS8-M25RS8, and M1RS9-M25RS9 performed better than models 1-25 with an average of $14.72 \%, 10.88 \%$, and $13.99 \%$ lower RMSE, respectively. Models M1RS11-M25RS11, M1RS12-M25RS12, and M1RS14-M25RS14 outperformed models 1-25 with an average of $14.99 \%, 18.12 \%$, and 13.84\% higher accuracy, respectively. While models M1RS7-M25RS7, and M1RS10-M25RS10 generated similar estimations to models 1-25. These results further indicated that combining the cloud optical thickness and meteorological variables enhanced the performance of the sunshine-based models, while incorporations of cloud fraction, aerosol optical depth, and precipitable water vapor amount accounted less for the improvement in estimation accuracy.

In the case that sunshine duration data were unavailable, the integrated models combining the meteorological variables and the atmospheric constituents had the average RMSE of $1.242 \mathrm{MJ} \mathrm{m}^{-2}$ and the average RRMSE of $12.31 \%$, which were lower than the corresponding values of $1.574 \mathrm{MJ} \mathrm{m}^{-2}$ and 
average RRMSE of $15.61 \%$ for models 26-43, suggesting that incorporation of atmospheric constituents into the temperature-based models improved the estimation accuracy. Overall, model M42RS15 generated the best estimations with the lowest RMSE of $0.903 \mathrm{MJ} \mathrm{m}^{-2}$ and the RRMSE of $8.95 \%$.

Models M26RS1-M43RS1, M26RS2-M43RS2, and M26RS4-M43RS4 had the average RMSE of 1.282 $\mathrm{MJ} \mathrm{m}^{-2}, 1.388 \mathrm{MJ} \mathrm{m}^{-2}$, and $1.414 \mathrm{MJ} \mathrm{m}^{-2}$, respectively, which were lower than $1.574 \mathrm{MJ} \mathrm{m}^{-2}$ for models 26-43. This suggested that combining the cloud fraction, cloud optical thickness, and precipitable water vapor amount and meteorological variables increased the estimation accuracy of the temperature-based models, which was further indicated by the better performances of models M26RS5-M43RS5, M26RS7-M43RS7, M26RS9-M43RS9, and M26RS12-M43RS12 over models 26-43. The improvement was more pronounced for incorporation of cloud fraction which decreased the RMSE of models $26-43$ by $17.65 \%$. Models M26RS3-M43RS3 performed similarly to models $26-43$, implying that inclusion of aerosol optical depth did not markedly affect the performances of the temperature-based models. The similar performances of models M26RS6-M43RS6, M26RS8-M43RS8, and M26RS10-M43RS10 to the corresponding models M26RS1-M43RS1, M26RS2-M43RS2, and M26RS4-M43RS4 further confirmed this result.

4 Concluding remarks

This study coupled the meteorological variables with the MODIS atmospheric products to estimate global solar radiation. 25 sunshine-based empirical models and 18 temperature-based empirical models were collected. A total of 645 coupled models incorporating cloud fraction, cloud optical depth, aerosol optical depth and precipitable water vapor amount into those empirical models were developed. The researched models were evaluated and compared at Chongqing in the Three Gorges Reservoir Area in China. The results suggested that the coupled models markedly outperformed the sunshine-based and temperature-based models, and incorporation of atmospheric constituents enhanced the performance of 
empirical models. The average RMSE decreased from $1.269 \mathrm{MJ} \mathrm{m}^{-2}$ for the empirical models to 1.071

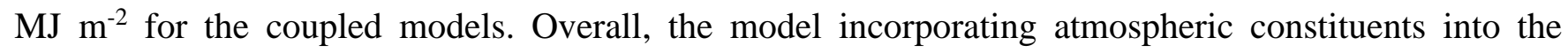
model proposed by Ouali and Alkama [67] generated the best estimation with the lowest RMSE of 0.817 $\mathrm{MJ} \mathrm{m}^{-2}$ and the RRMSE of $8.11 \%$. In the case that sunshine duration data was unavailable, the model integrating atmospheric constituents with the model suggested by Chen and $\mathrm{Li}$ [30] was the most accuracy one with the lowest RMSE of $0.903 \mathrm{MJ} \mathrm{m}^{-2}$ and the RRMSE of $8.95 \%$. If all the meteorological variables were available, the model RS15 using all the atmospheric constituents can be used to estimate global solar radiation with reasonable accuracy.

The main novelty of this study is that this is so far the first effort to explore the estimation of global solar radiation combining the MODIS atmospheric products with meteorological variables, and to develop coupled models incorporating the atmospheric constituents into empirical models. Moreover, the most accurate models under different scenarios of data availability were proposed. The results demonstrated that coupling remote sensing with the meteorological variables can enhance the performance of conventional empirical models, which may provide a promising alternative to generate global solar radiation data with better accuracy.

Due to the simplicity, operability and reasonable accuracy, empirical model was the most widely used method in estimating solar radiation. In recent years, many studies investigated the performances of machine learning algorithms such as back-propagation algorithms, extreme learning machines and random forests, and the results showed a great potential in estimating global solar radiation. Thus, it is important for the future works to couple remote sensing with the ground measurements of meteorological variables to estimate solar radiation using machine learning algorithms.

Acknowledgment 
The work was supported by Youth Innovation Promotion Association (2018417), National Natural

Science Foundation of China (41771460, 41901130, 41701247), Open fund by Jiangsu Key Laboratory 510 of Atmospheric Environment Monitoring and Pollution Control (KHK1806), and Open Fund for Key

Laboratory of Mine Geological Disasters and Prevention and Control (2018-08). A Project Funded by 512 the Priority Academic Program Development of Jiangsu Higher Education Institutions (PAPD). We thank the National Meteorological Information Center for providing the long-term meteorological measurements records. We thank NASA Earth Observing System Data and Information System for providing the long-term atmospheric product. Many thanks go to the anonymous reviewers for the 516 comments on the manuscript. machine in an arid climate. Energy Convers Manag 2016; 118:105-18. predicting daily global solar radiation in humid regions. Energy Convers Manag 2019; 183: 280-95.

[3] Sun Huaiwei,Gui Dongwei, Yan Baowei.Assessing the potential of random forest method for estimating solar radiation using air pollution index. Energy Convers Manag 2019; 119: 121-9. 
[4] Yao Wanxiang, Zhang Chunxiao, Wang Xiao.The research of new daily diffuse solar radiation models modified by air quality index (AQI) in the region with heavy fog and haze. Energy Convers Manag 2017; 139:140-50.

[5] Yao WX, Zhang CX, Wang X, Zhang ZG, Li XL, Di HY. A new correlation between global solar radiation and the quality of sunshine duration in China. Energy Convers Manag 2018; 164:579-87.

[6] Chen JL, Li GS, Wu SJ. Assessing the potential of support vector machine for estimating daily solar radiation using sunshine duration. Energy Convers Manage 2013; 75: 311-18.

[7] Alonso-Montesinos J, Batlles FJ, Bosch JL. Beam, diffuse and global solar irradiance estimation with satellite imagery. Energy Convers Manag 2015; 105:1205-12.

[8] Mahmoudinezhad S, Rezania A, Rosendahl LA. Behavior of hybrid concentrated photovoltaic-thermoelectric generator under variable solar radiation. Energy Convers Manag 2018; 164: 443-52.

[9] Yang ZM, Li WY, Chen XH, Su SH, Lin GX, Chen JC. Maximum efficiency and parametric optimum selection of a concentrated solar spectrum splitting photovoltaic cell-thermoelectric generator system. Energy Convers Manag 2018; 174: 65-71.

[10] Renno C, Petit F, Gatto A. Artificial neural network models for predicting the solar radiation as input of a concentrating photovoltaic system. Energy Convers Manag 2015; 106: 999-1012.

[11] Ismail TM, Ramzy K, Elnaghi BE, Abelwhab MN, El-Salam M. Using MATLAB to model and simulate a photovoltaic system to produce hydrogen. Energy Convers Manag 2019; 185:101-29.

[12] Mousavi SM, Mostafavi ES,Jiao PC. Next generation prediction model for daily solar radiation on horizontal surface using a hybrid neural network and simulated annealing method. Energy Convers Manag 2017; 153: 671-82. 
[13] Fan JL, Wang XK, Wu LF, Zhou HM, Zhang FC, Yu X, Lu XH, Xiang YZ. Comparison of Support Vector Machine and Extreme Gradient Boosting for predicting daily global solar radiation using temperature and precipitation in humid subtropical climates: A case study in China. Energy Convers Manag 2018; 164: 102-11.

[14] Zhou Y, Wang DJ, Liu YF, Liu JP. Diffuse solar radiation models for different climate zones in China: Model evaluation and general model development. Energy Convers Manag 2019; 185: 518-36.

[15] Alsina EF, Bortolini M, Gamberi M, Regattieri A. Artificial neural network optimization for monthly average daily global solar radiation prediction. Energy Convers Manag 2016; 120: 320-9.

[16] Angstrom A. Solar and terrestrial radiation. Q J Roy Meteor Soc 924; 50: 121-6.

[17] Prescott JA. Evaporation from a water surface in relation to solar radiation. T Roy Soc South Aust 1940; 64: 114-8.

[18] Almorox J, Hontoria C. Global solar radiation estimation using sunshine duration in Spain. Energy Convers Manag 2004; 45: 1529-35.

[19] Ampratwum DB, Dorvio ASS. Estimation of solar radiation from the number of sunshine hours. Appl Energ 1999; 63: 161-7.

[20] Ögelman H, Ecevit A, Tasdemiro E. A new method for estimating solar radiation from bright sunshine data. Sol Energy 1984; 33: 619-25.

[21] Bahel V, Bakhsh H, Srinivasan R. A correlation for estimation of global solar radiation. Energy $1987 ; 12: 131-5$.

[22] Newland FJ. A study of solar radiation models for the coastal region of South China. Sol Energy 1988; 31: 227-35. 
[23] Chen JL, He L, Yang H, Ma M, Chen Q, Wu S J, Xiao ZL. Empirical models for estimating monthly global solar radiation: a most comprehensive review and comparative case study in China. Renew Sustain Energy Rev 2019; 108: 91-111.

[24] Yorukoglu M, Celik AN. A critical review on the estimation of daily global solar radiation from sunshine duration. Energy Convers. Manage. 2006; 47: 2441-50.

[25] Zhou J, Wu YZ, Yan G. General formula for estimation of monthly average daily global solar radiation in China. Energy Convers. Manage. 2005; 46:257-68.

[26] Lee Khil-Ha. Improving the correlation between incoming solar radiation and sunshine hour using DTR. Int J Climatol 2015; 35(3): 361-74.

[27] Saffaripour MH, Mehrabian MA, Bazargan. Predicting solar radiation fluxes for solar energy system applications. Int J Environ Scu Te 2013; 10(4): 761-8.

[28] Bakirci K. Prediction of global solar radiation and comparison with satellite data. J Atmos Sol-Terr Phy 2017; 152: 41-9.

[29] Liu JD, Liu JM, Linderholm HW, Chen DL, Yu Q, Wu DG. Observation and calculation of the solar radiation on the Tibetan plateau. Energy Convers Manag 2012: 57(2): 23-32.

[30] Chen JL, Li GS. Estimation of monthly average daily solar radiation from measured meteorological data in Yangtze River Basin in China. Int J Climatol 2013; 33: 487-98.

[31] Falayi EO, Adepitan JO, Rabiu AB. Empirical models for the correlation of global solar radiation with meteorological data for Iseyin, Nigeria. Int J Phys Sci 2008; 3: 210-6.

[32] Ouali K, Alkama R. A new model of global solar radiation based on meteorological data in Bejaia City (Algeria). Energy Procedia 2014; 50: 670-6. 
[33] Khorasanizadeh H, Mohammadi K, Jalilvand M. A statistical comparative study to demonstrate the merit of day of the year-based models for estimation of horizontal global solar radiation. Energy Convers Manag 2014; 87: 37-47.

[34] Hargreaves GH, Samani ZA. Estimating potential evaporation. J Irrig Drain Eng 1982; 108: 225-30.

[35] Bristow KL, Campbell GS. On the relationship between incoming solar radiation and daily maximum and minimum temperature. Agr For Meteorol 1984; 31:159-66.

[36] Fan J, Chen B, Wu L, Zhang F, Lu X, Xiang Y. Evaluation and development of temperature-based empirical models for estimating daily global solar radiation in humid regions. Energy 2018; 144 : 903-14.

[37] Hunt LA, Kuchar L, Swanton CJ. Estimation of solar radiation for use in crop modeling. Agr For Meteorol 1998; 91: 293-300.

[38] Thornton PE, Running SW. An improved algorithm for estimating incident daily solar radiation from measurements of temperature, humidity, and precipitation. Agr For Meteorol 1999; 93: 211-28.

[39] Ball RA, Purcell LC, Carey SK. Evaluation of Solar radiation prediction models in North America. Agronomy Journal 2004; 96: 391-7.

[40] Chen JL, He L, Chen Q, Lv MQ, Zhu HL, Wen ZF, Wu SJ. Study of monthly mean daily diffuse and direct beam radiation estimation with MODIS atmospheric product. Renew Energ 2018; 132: 221-32.

[41] Bayrakçı HC, Demircan C, Keçebaş A. The development of empirical models for estimating global solar radiation on horizontal surface: a case study. Renew Sustain Energy Rev 2018; 81: 2771-82. 
612 [42] Chen JL, Xiao BB, Chen CD, Wen ZF, Jiang Y, Lv MQ, Li GS. Estimation of monthly-mean 613 global solar radiation using MODIS atmospheric product over China. J Atmos Sol-Terr Phy $614 \quad 2014 ; 110: 63-80$.

[43] Chen JL, Li GS. Parameterization and mapping of solar radiation in data sparse regions. Asia-Pac J Atmos Sci. 2012; 48(4): 423-31.

[50] Platnick S, Meyer KG, King MD, Wind G, Amarasinghe N, Marchant B. The MODIS cloud optical and microphysical products: Collection 6 updates and examples from Terra and Aqua. IEEE Trans. Geosci. Remote Sens. 2017; 55: 502-25.

[51] Ghimire S, Deo RC, Downs NJ, Ra N. Self-adaptive differential evolutionary extreme learning machines for long-term solar radiation prediction with remotely-sensed modis satellite and reanalysis atmospheric products in solar-rich cities. Remote Sensing of Environment 2018; 212, 176-98. 
634 [52] Ravinesh CD, Mehmet S. Forecasting long-term global solar radiation with an ANN algorithm 635 coupled with satellite-derived (MODIS) land surface temperature (LST) for regional locations in 636 Queensland. Renew Sustain Energy Rev 72 (2017) 828-48.

637 [53] Zhou Q, Flores A, Glenn NF, Walters R, Han B. A machine learning approach to estimation of 638 downward solar radiation from satellite-derived data products: An application over a semi-arid 639 ecosystem in the U.S. PLoS ONE 2017; 12(8): e0180239.

640 [54] Qin, WM, Wang LC, Lin AW, Zhang M, Xia XG, Hu B, Niu ZG. Comparison of deterministic and

[55] Chen M, Zhuang QL, He YJ. An Efficient Method of Estimating Downward Solar Radiation Based on the MODIS Observations for the Use of Land Surface Modeling. Remote Sens. 2014, 6: 7136-57.

[56] Allen RG, Pereira LS, Raes D, Smith M. Crop evapotranspiration guidelines for computing crop water requirements e FAO irrigation and drainage paper 56. Rome: Food and Agriculture Organization of the United Nations; 1998.

[57] Bakirci K. Correlations for estimation of daily global solar radiation with hours of bright sunshine in Turkey. Energy 2009; 34(4): 485-501.

[58] Olayinka S. Estimation of global and diffuse solar radiations for selected cities in Nigeria. Int J Energy Environ Eng 2011; 3: 13-33.

[59] Abdallah YAG. New correlation of global solar radiation with meteorological parameters for Bahrain, Sol Energy 1994; 16:111-20.

[60] Swartman RK, Ogunlade O. Solar radiation estimates from common parameters, Sol Energy 1967; 11:170-72. 
[61] Al-Salihi AM, Kadum MM, Mohammed AJ. Estimation of global solar radiation on horizontal surface using routine meteorological measurements for different cities in Iraq. Asian J Sci Res 2010; 3(4): 240-48.

[62] Chen R, Kang E, Ji X, Yang J, Zhang Z. Trends of the global radiation and sunshine hours in 1961-1998 and their relationships in China. Energy Convers Manag 2006; 47: 2859-66.

[63] Okonkwo GN, Nwokoye AOC. Estimating global solar radiation from temperature data in Minna location. Eur Sci J 2014; 10: 254-64.

[64] Kirmani S, Jamil M, Rizwan M. Empirical correlation of estimating global solar radiation using meteorological parameters. Int J Sustain Energy 2015; 34(5):327-39.

[65] Chen JL, Li GS. Evaluation of support vector machine for estimation of solar radiation from measured meteorological variables. Theor Appl Climatol 2014; 115: 627-38.

[66] Adeala AA, Huan Z, Enweremadu CC. Evaluation of global solar radiation using multiple weather parameters as predictors for South Africa Provinces. Therm Sci 2015; 19: 495-509.

[67] Ouali K, Alkama R. A new model of global solar radiation based on meteorological data in Bejaia City, Algeria. J Sol Energy 2014; 1-9.

[68] Awachie IRN, Okeke CE. New empirical solar model and its use in predicting global solar irradiation. Niger J Sol Energy 1990; 9: 143-56.

[69] Ohunakin OS, Adaramola MS, Oyewolu OM, Fagbenle RO. Correlations for estimating solar radiation using sunshine hours and temperature measurement in OSogbo, Osun state, Nigeria. Front Energy 2013:1-9.

[70] Li MF, Liu HB, Guo PT, Wu W. Estimation of daily solar radiation from routinely observed meteorological data in Chongqing, China. Energy Convers Manage 2010; 51(12):2575-79. 
[71] Okundamiya MS, Nzeako AN. Estimation of diffuse solar radiation for selected cities in Nigeria. ISRN Renew Energy 2011; 439410.

[72] El-Sebaii AA, Al-Ghamdi AA, Al-Hazmi FS, Faidah A. Estimation of global solar radiation on horizontal surfaces in Jeddah, Saudi Arabia. Energy Policy 2009; 37: 3645-49.

[73] Korachagaon I, Bapat VN. General formula for the estimation of global solar radiation on earth's surface around the globe. Renew Energ 2012; 41(4): 394-400.

[74] Amillo AG, Huld T, Müller R. A New Database of Global and Direct Solar Radiation Using the Eastern Meteosat Satellite, Models and Validation. Remote Sensing 2014; 6: 8165-89.

[75] He HP, Wu SJ, Ma MH, Wen ZF, Lv MQ, Chen JL. Spatial distribution and temporal trend of pan evaporation in the three gorges reservoir area and its surroundings during 1952-2013. Appl Ecol Env Res 2017; 15(3):1594-610.

[76] King MD, Tsay SC, Platnick SE, Wang M, Liou KN. Cloud Retrieval Algorithms for MODIS: Optical Thickness, Effective Particle Radius, and Thermodynamic Phase. MODIS Algorithm Theoretical Basis Document, ATBD-MOD-05, NASA.1997.

[77] Gao BC, Kaufman YJ. The MODIS Near-IR Water Vapor Algorithm. MODIS Algorithm Theoretical Basis Document, ATBD-MOD-03, NASA.1998.

[78] Chen JL, Liu $\mathrm{HB}, \mathrm{Wu} \mathrm{W}$, Xie DT. Estimation of monthly solar radiation from measured temperatures using support vector machines-A case study. Renew Energ 2011; 36(1): 413-20.

[79] Liu XY, Mei XR, Li YZ, Wang QS, Jensen JR, Zhang XQ. Evaluation of temperature-based global solar radiation models in China. Agr For Meteorol 2009; 149:1433-46.

[80] Stanhill G, Cohen S. Global dimming: a review of the evidence for a widespread and significant reduction in global radiation with discussion of its probable causes and possible agricultural consequences. Agric For Meteorol. 2001; 107: 255-78. 
[81] Qin J, Chen Z, Yang K, Liang S, Tang W. Estimation of monthly-mean daily global solar radiation based on MODIS and TRMM products. Appl Energ 2011; 88: 2480-89.

703

[82] Feng S, Hu Q, Qian W. Quality control of daily meteorological data in China, 1951-2000: a new dataset. Int J Climatol 2004; 24(7): 853-70.

[83] Tang W, Yang K, He J, Qin J. Quality control and estimation of global solar radiation in China. Sol Energy 2010; 84(3): 466-75.

[84] Besharat F, Dehghan AA, Faghih AR. Empirical models for estimating global solar radiation: a review and case study. Renew Sustain Energy Rev 2013; 21(21): 798-821.

[85] Chen RS, Ersi K, Yang JP, Lu SH, Zhao WZ. Validation of five global radiation models with measured daily data in China. Energy Convers Manage 2004; 45:1759-69.

[86] Boluwaji MO, Onyedi DO. Comparative study of ground measured, satellite derived, and estimated global solar radiation data in Nigeria. J Sol Energy 2016; 10: 1-7.

[87] Wu G, Liu Y, Wang T. Methods and strategy for modeling daily global solar radiation with measured meteorological data - a case study in Nanchang station, China. Energy Convers Manag 2007; 48: 2447-52.

[88] Meenal R, Selvakumar AI. Assessment of SVM, empirical and ANN based solar radiation prediction models with most influencing input parameters. Renew Energ 2018; 121: 324-43.

[89] Chen RS, Ersi K, Yang JP, Lu SH, Zhao WZ. Validation of five global radiation models with measured daily data in China. Energy Convers Manage 2004; 45:1759-69.

[90] Iziomon MG, Mayer H. Performance of solar radiation models - a case study. Agric For Meteorol $2001 ; 10,1-11$. 
Table 1 Formulas for estimating global solar radiation using atmospheric constituents

\begin{tabular}{|c|c|c|c|}
\hline Model ID & Equation $^{\text {a }}$ & RMSE & RRMSE \\
\hline $\mathrm{RS} 1$ & $\mathrm{Rs} / \mathrm{Ra}=\mathrm{a}+\mathrm{b}_{1} \mathrm{CF}$ & 1.828 & $18.12 \%$ \\
\hline $\mathrm{RS} 2$ & $\mathrm{Rs} / \mathrm{Ra}=\mathrm{a}+\mathrm{b}_{1} \mathrm{COT}$ & 2.237 & $22.18 \%$ \\
\hline RS3 & $\mathrm{Rs} / \mathrm{Ra}=\mathrm{a}+\mathrm{b}_{1} \mathrm{AOT}$ & 2.889 & $28.64 \%$ \\
\hline RS4 & $\mathrm{Rs} / \mathrm{Ra}=\mathrm{a}+\mathrm{b}_{1} \mathrm{PW}$ & 2.387 & $23.66 \%$ \\
\hline RS5 & $\mathrm{Rs} / \mathrm{Ra}=\mathrm{a}+\mathrm{b}_{1} \mathrm{CF}+\mathrm{COT}$ & 1.498 & $14.85 \%$ \\
\hline RS6 & $\mathrm{Rs} / \mathrm{Ra}=\mathrm{a}+\mathrm{b}_{1} \mathrm{CF}+\mathrm{AOT}$ & 1.815 & $17.99 \%$ \\
\hline RS7 & $\mathrm{Rs} / \mathrm{Ra}=\mathrm{a}+\mathrm{b}_{1} \mathrm{CF}+\mathrm{PW}$ & 1.497 & $14.84 \%$ \\
\hline RS8 & $\mathrm{Rs} / \mathrm{Ra}=\mathrm{a}+\mathrm{COT}+\mathrm{AOT}$ & 2.147 & $21.28 \%$ \\
\hline RS9 & $\mathrm{Rs} / \mathrm{Ra}=\mathrm{a}+\mathrm{COT}+\mathrm{PW}$ & 1.952 & $19.35 \%$ \\
\hline RS10 & $\mathrm{Rs} / \mathrm{Ra}=\mathrm{a}+\mathrm{AOT}+\mathrm{PW}$ & 2.391 & $23.70 \%$ \\
\hline RS11 & $\mathrm{Rs} / \mathrm{Ra}=\mathrm{a}+\mathrm{CF}+\mathrm{COT}+\mathrm{AOT}$ & 1.464 & $14.52 \%$ \\
\hline $\mathrm{RS} 12$ & $\mathrm{Rs} / \mathrm{Ra}=\mathrm{a}+\mathrm{CF}+\mathrm{COT}+\mathrm{PW}$ & 1.269 & $12.58 \%$ \\
\hline RS13 & $\mathrm{Rs} / \mathrm{Ra}=\mathrm{a}+\mathrm{CF}+\mathrm{AOT}+\mathrm{PW}$ & 1.495 & $14.82 \%$ \\
\hline $\mathrm{RS} 14$ & $\mathrm{Rs} / \mathrm{Ra}=\mathrm{a}+\mathrm{COT}+\mathrm{AOT}+\mathrm{PW}$ & 1.948 & $19.31 \%$ \\
\hline $\mathrm{RS} 15$ & $\mathrm{Rs} / \mathrm{Ra}=\mathrm{a}+\mathrm{CF}+\mathrm{COT}+\mathrm{AOT}+\mathrm{PW}$ & 1.267 & $12.56 \%$ \\
\hline
\end{tabular}

${ }^{\text {a }}$ Rs, Ra, CF, COT, PWV and AOT are monthly mean global solar radiation, extraterrestrial solar thickness, respectively. 
Table 2 The coupled models incorporating atmospheric constituents into the empirical models

\begin{tabular}{|c|c|c|c|c|c|c|c|c|c|c|c|c|c|c|c|}
\hline $\begin{array}{c}\text { Empirical } \\
\text { model }\end{array}$ & RS1 & $\$ 2$ & S3 & RS4 & RS5 & 6 & 7 & S8 & RS9 & 0 & S11 & 2 & $\mathrm{~S} 13$ & S14 & S15 \\
\hline M1 & 1RS1 & I1RS2 & I1RS3 & M1RS4 & 11RS5 & M1RS6 & $11 \mathrm{RS} 7$ & M1RS8 & I1RS9 & $11 \mathrm{RS} 10$ & M1RS11 & I1RS12 & I1RS13 & M1RS14 & RS15 \\
\hline M2 & M2RS1 & M2RS2 & M2RS3 & M2RS4 & [2RS5 & I2RS6 & M2RS7 & M2RS8 & I2RS9 & I2RS10 & M2RS11 & I2RS12 & M2RS13 & I2RS14 & 12RS15 \\
\hline M3 & M3RS1 & M3RS2 & M3RS3 & M3RS4 & M3RS5 & M3RS6 & M3RS7 & M3RS8 & I3RS9 & M3RS10 & M3RS11 & M3RS12 & M3RS13 & M3RS14 & M3RS15 \\
\hline M4 & M4RS1 & M4RS2 & M4RS3 & M4RS4 & M4RS5 & M4RS6 & M4RS7 & M4RS8 & M4RS9 & M4RS10 & M4RS11 & M4RS12 & M4RS13 & M4RS14 & M4RS15 \\
\hline M5 & M5RS1 & M5RS2 & M5RS3 & M5RS4 & M5RS5 & M5RS6 & M5RS7 & M5RS8 & M5RS9 & M5RS10 & M5RS11 & M5RS12 & M5RS13 & & \\
\hline M6 & M6RS1 & M6RS2 & M6RS3 & M6RS4 & M6RS5 & M6RS6 & M6RS7 & M6RS8 & M6RS9 & M6RS10 & M6RS11 & M6RS12 & M6RS13 & M6RS14 & M6RS15 \\
\hline M7 & M7RS1 & M7RS2 & M7RS3 & M7RS4 & M7RS5 & M7RS6 & M7RS7 & M7RS8 & M7RS9 & M7RS10 & M7RS11 & M7RS12 & M7RS13 & M7RS14 & M7RS15 \\
\hline M8 & M8RS1 & M8RS2 & M8RS3 & M8RS4 & M8RS5 & M8RS6 & M8RS7 & M8RS8 & I8RS9 & M8RS10 & M8RS11 & M8RS12 & M8RS13 & M8RS14 & M8RS15 \\
\hline M9 & & M9RS2 & M9RS3 & & & & M9RS7 & M9RS8 & 1970 & & & & & & \\
\hline M10 & M10RS1 & M10RS2 & M10RS3 & M10RS4 & M10RS5 & M10RS6 & M10RS7 & M10RS8 & M10RS9 & M10RS10 & M10RS11 & M10RS12 & M10P & S14 & S15 \\
\hline M11 & M11RS1 & M11RS2 & M11RS3 & M11RS4 & M11RS5 & M11RS6 & M11RS7 & M11RS8 & M11RS9 & M11RS10 & M11RS11 & M11RS12 & M11RS13 & M11RS14 & M11RS15 \\
\hline M12 & M12RS1 & M12RS2 & M12RS3 & M12RS4 & M12RS5 & M12RS6 & M12RS7 & M12RS8 & M12RS9 & M12RS10 & M12RS11 & M12RS12 & M12RS13 & M12RS14 & M12RS15 \\
\hline M13 & M13RS1 & M13RS2 & M13RS3 & M13RS4 & M13RS5 & M13RS6 & M13RS7 & M13RS8 & M13RS9 & M13RS10 & M13RS11 & M13RS12 & M13RS13 & M13RS14 & M13RS15 \\
\hline 10 & M14RS1 & M14RS2 & & M14RS4 & M14RS5 & M14RS6 & M14RS7 & M14RS8 & M14RS9 & M14RS10 & M14RS11 & M14RS12 & M14RS13 & M14RS14 & M14RS15 \\
\hline M15 & M15RS1 & M15RS2 & M15RS3 & M15RS4 & M15RS5 & M15RS6 & M15RS7 & M15RS8 & M15RS9 & M15RS10 & M15RS11 & M15RS12 & M15RS13 & M15RS14 & M15 \\
\hline M16 & M16RS1 & M16RS2 & M16RS3 & M16RS4 & M16RS5 & M16RS6 & M16RS7 & M16RS8 & M16RS9 & M16RS10 & M16RS11 & M16RS12 & M16RS13 & M16RS14 & M16RS15 \\
\hline M17 & M17RS1 & M17RS2 & M17RS3 & M17RS4 & & M17RS6 & M17RS7 & M17RS8 & M17RS9 & M17RS10 & M17RS11 & & & M17RS14 & M17RS15 \\
\hline M18 & M18RS1 & M18RS2 & M18RS3 & M18RS4 & M18RS5 & M18RS6 & M18RS7 & M18RS8 & M18RS9 & M18RS10 & M18RS11 & M18RS12 & M18RS13 & M18RS14 & M18RS15 \\
\hline M19 & M19RS1 & M19RS2 & M19RS3 & M19RS4 & M19RS5 & M19RS6 & M19RS7 & M19RS8 & M19RS9 & M19RS10 & M19RS11 & M19RS12 & M19RS13 & M19RS14 & M19RS15 \\
\hline M20 & M20RS1 & M20RS2 & M20RS3 & M20RS4 & M20RS5 & M20RS6 & M20RS7 & M20RS8 & M20RS9 & M20RS10 & M20RS11 & M20RS12 & M20RS13 & M20RS14 & M20RS15 \\
\hline M21 & $\mathrm{M} 21 \mathrm{RS} 1$ & M21RS2 & M21RS3 & M21RS4 & M21RS5 & M21RS6 & M21RS7 & M21RS8 & M21RS9 & M21RS10 & M21RS11 & M21RS12 & M21RS13 & M21RS14 & M21RS15 \\
\hline M22 & M22RS1 & M22RS2 & $\mathrm{M} 22 \mathrm{RS} 3$ & M22RS4 & M22RS5 & M22RS6 & M22RS7 & M22RS8 & M22RS9 & M22RS10 & M22RS11 & M22RS12 & M22RS13 & M22RS14 & M22RS15 \\
\hline
\end{tabular}


Table 2 The coupled models incorporating atmospheric constituents into the empirical models (continued)

\begin{tabular}{|c|c|c|c|c|c|c|c|c|c|c|c|c|c|c|c|}
\hline mode & & & & & & & & & & & & & & & \\
\hline & 1 & 2 & 3 & 4 & 5 & 5 & & 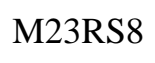 & & & & & & & \\
\hline & & & & & & & & & & & & & & & \\
\hline 5 & $5 \mathrm{RS} 1$ & $5 \mathrm{RS} 2$ & $5 \mathrm{RS} 3$ & $25 \mathrm{RS} 4$ & 25RS5 & 25RS6 & $5 \mathrm{RS} 7$ & 5RS8 & 25RS9 & 10 & 25RS11 & & & & \\
\hline M26 & 6 & 6 & 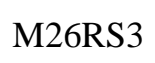 & & & 26RS6 & & & & & & & & & \\
\hline & & & & & & & & & & & & & & & \\
\hline & & $\mathrm{S} 2$ & $\mathrm{RS} 3$ & & & & RS7 & & & & & & & & \\
\hline M29 & ORS1 & $9 \mathrm{RS} 2$ & $29 \mathrm{RS} 3$ & 29RS4 & 29RS5 & 9 RS6 & 29RS7 & RS8 & RS9 & 10 & 11 & 2 & 13 & 4 & \\
\hline M30 & & & & & & & & & 1 & & & & & & \\
\hline & & & & & & & & & & & & & & & \\
\hline & & & & & & & & & & & & & & & \\
\hline 33 & & $33 R S 2$ & 33RS3 & M33RS4 & I33RS5 & 33RS6 & 33RS7 & & RS9 & & & & & & \\
\hline M34 & $4 \mathrm{RS} 1$ & 34RS2 & $34 \mathrm{RS} 3$ & M34RS4 & I34RS5 & 34RS6 & 34RS7 & M34RS8 & M34RS9 & 1 & & $\$ 12$ & 3 & & $\mathrm{RS} 15$ \\
\hline & & & & & & & & & & & & & & & \\
\hline 10 & & & & & & & & & & & & & & & \\
\hline 87 & & & & & & & & & & & & & & & \\
\hline & & & & & & & & & & & & & & & \\
\hline & & & & & & & & & & & & & & & \\
\hline & & & & & & & & & & & & & & & \\
\hline & & & & M41RS4 & & M41RS6 & & $1 \mathrm{RS} 8$ & M41RS9 & M41RS10 & M41RS11 & M41RS12 & M41RS13 & M41RS14 & \\
\hline & & & & & & & & & & & & & & & M42RS \\
\hline M43 & M43RS1 & M43RS2 & M43RS3 & M43RS4 & M43RS5 & M43RS6 & M43RS7 & M43RS8 & M43RS9 & M43RS10 & M43RS11 & M43RS12 & M43RS13 & M43RS14 & M43RS \\
\hline
\end{tabular}


Table 3 Performance of the collected empirical models

\begin{tabular}{|c|c|c|c|c|c|}
\hline $\begin{array}{c}\text { Empirical } \\
\text { model }\end{array}$ & RMSE & RRMSE & $\begin{array}{c}\text { Empirical } \\
\text { model }\end{array}$ & RMSE & RRMSE \\
\hline Model 1 & 1.129 & $11.19 \%$ & Model 26 & 1.621 & $16.07 \%$ \\
\hline Model 2 & 1.129 & $11.19 \%$ & Model 27 & 1.94 & $19.23 \%$ \\
\hline Model 3 & 1.128 & $11.18 \%$ & Model 28 & 2.099 & $20.81 \%$ \\
\hline Model 4 & 1.129 & $11.19 \%$ & Model 29 & 1.801 & $17.86 \%$ \\
\hline Model 5 & 1.127 & $11.18 \%$ & Model 30 & 1.532 & $15.19 \%$ \\
\hline Model 6 & 1.041 & $10.32 \%$ & Model 31 & 1.523 & $15.10 \%$ \\
\hline Model 7 & 1.05 & $10.41 \%$ & Model 32 & 1.796 & $17.81 \%$ \\
\hline Model 8 & 1.031 & $10.22 \%$ & Model 33 & 1.404 & $13.92 \%$ \\
\hline Model 9 & 1.015 & $10.07 \%$ & Model 34 & 1.315 & $13.04 \%$ \\
\hline Model 10 & 1.124 & $11.14 \%$ & Model 35 & 1.981 & $19.64 \%$ \\
\hline Model 11 & 1.055 & $10.46 \%$ & Model 36 & 1.631 & $16.17 \%$ \\
\hline Model 12 & 0.969 & $9.60 \%$ & Model 37 & 1.31 & $12.98 \%$ \\
\hline Model 13 & 0.997 & $9.89 \%$ & Model 38 & 1.471 & $14.58 \%$ \\
\hline Model 14 & 1.077 & $10.68 \%$ & Model 39 & 1.612 & $15.98 \%$ \\
\hline Model 15 & 0.98 & $9.71 \%$ & Model 40 & 1.581 & $15.67 \%$ \\
\hline Model 16 & 1.067 & $10.58 \%$ & Model 41 & 1.37 & $13.59 \%$ \\
\hline Model 17 & 1.113 & $11.03 \%$ & Model 42 & 1.154 & $11.44 \%$ \\
\hline Model 18 & 1.111 & $11.02 \%$ & Model 43 & 1.194 & $11.84 \%$ \\
\hline Model 19 & 0.972 & $9.64 \%$ & & & \\
\hline Model 20 & 1.028 & $10.19 \%$ & & & \\
\hline Model 21 & 1.04 & $10.31 \%$ & & & \\
\hline Model 22 & 0.979 & $9.70 \%$ & & & \\
\hline Model 23 & 1.012 & $10.03 \%$ & & & \\
\hline Model 24 & 0.968 & $9.60 \%$ & & & \\
\hline Model 25 & 0.967 & $9.58 \%$ & & & \\
\hline
\end{tabular}


741 Table 4 The RMSE (MJ m ${ }^{-2}$ ) of the coupled models

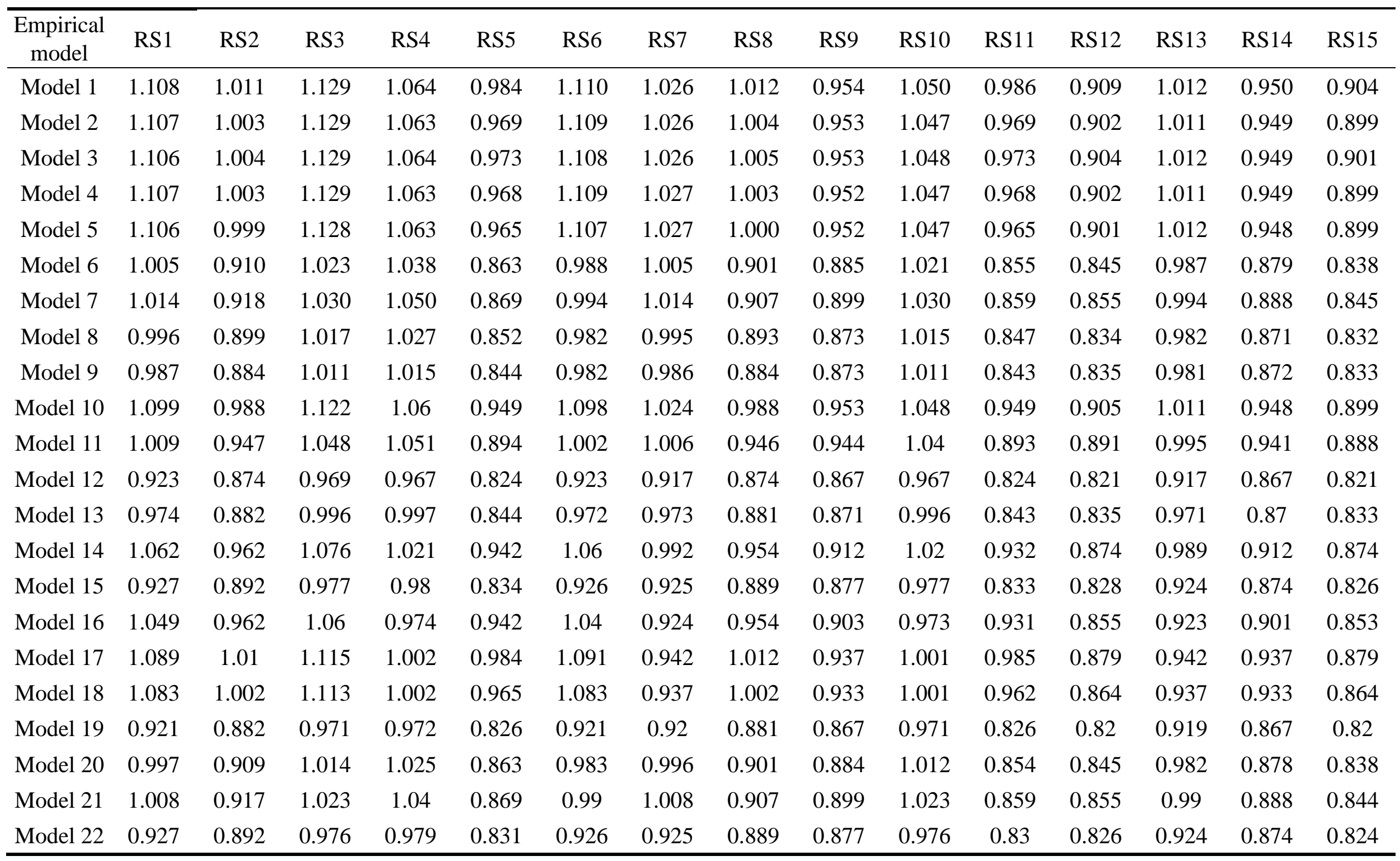


742 Table 4 The RMSE (MJ ${ }^{-2}$ ) of the coupled models (continued)

\begin{tabular}{|c|c|c|c|c|c|c|c|c|c|c|c|c|c|c|c|}
\hline $\begin{array}{c}\text { Empirical } \\
\text { model }\end{array}$ & RS1 & $\mathrm{RS} 2$ & RS3 & RS4 & RS5 & RS6 & RS7 & RS8 & RS9 & RS10 & RS11 & RS12 & RS13 & RS14 & RS15 \\
\hline Model 23 & 0.954 & 0.930 & 1.011 & 0.977 & 0.877 & 0.954 & 0.922 & 0.928 & 0.905 & 0.976 & 0.875 & 0.854 & 0.921 & 0.903 & 0.852 \\
\hline Model 24 & 0.920 & 0.882 & 0.968 & 0.968 & 0.829 & 0.920 & 0.919 & 0.882 & 0.866 & 0.968 & 0.829 & 0.822 & 0.919 & 0.866 & 0.821 \\
\hline Model 25 & 0.920 & 0.882 & 0.968 & 0.968 & 0.825 & 0.920 & 0.918 & 0.881 & 0.866 & 0.968 & 0.825 & 0.818 & 0.918 & 0.865 & 0.817 \\
\hline Model 26 & 1.409 & 1.423 & 1.514 & 1.521 & 1.225 & 1.344 & 1.278 & 1.296 & 1.344 & 1.472 & 1.140 & 1.112 & 1.263 & 1.275 & 1.084 \\
\hline Model 27 & 1.410 & 1.593 & 1.925 & 1.662 & 1.165 & 1.397 & 1.351 & 1.591 & 1.269 & 1.653 & 1.162 & 1.054 & 1.340 & 1.268 & 1.052 \\
\hline Model 28 & 1.469 & 1.702 & 2.086 & 1.917 & 1.208 & 1.454 & 1.441 & 1.7 & 1.437 & 1.899 & 1.203 & 1.122 & 1.424 & 1.434 & 1.117 \\
\hline Model 29 & 1.353 & 1.489 & 1.791 & 1.529 & 1.118 & 1.344 & 1.287 & 1.488 & 1.188 & 1.528 & 1.116 & 1.01 & 1.284 & 1.185 & 1.01 \\
\hline Model 30 & 1.407 & 1.391 & 1.445 & 1.404 & 1.227 & 1.341 & 1.28 & 1.274 & 1.299 & 1.379 & 1.141 & 1.118 & 1.264 & 1.245 & 1.089 \\
\hline Model 31 & 1.393 & 1.362 & 1.434 & 1.379 & & & & 1.249 & & & & & & & 1.07 \\
\hline Model 32 & 1.337 & 1.592 & 1.742 & 1.381 & 1.165 & 1.296 & 1.201 & 1.587 & 1.228 & 1.319 & 1.162 & 1.043 & 1.15 & 1.214 & 1.035 \\
\hline Model 33 & 1.223 & 1.212 & 1.381 & 1.392 & 1.03 & 1.219 & 1.221 & 1.181 & 1.155 & 1.374 & 1.021 & 1.001 & 1.218 & 1.136 & 0.996 \\
\hline Model 34 & 1.182 & 1.177 & 1.283 & 1.306 & 1.022 & 1.173 & 1.181 & 1.14 & 1.129 & 1.279 & 1.011 & 0.995 & 1.172 & 1.104 & 0.988 \\
\hline Model 35 & 1.394 & 1.699 & 1.935 & 1.648 & 1.206 & 1.354 & 1.303 & 1.699 & 1.42 & 1.563 & 1.203 & 1.118 & 1.238 & 1.404 & 1.105 \\
\hline Model 36 & 1.273 & 1.475 & 1.576 & 1.225 & 1.117 & 1.235 & 1.118 & 1.466 & 1.108 & 1.189 & 1.114 & 0.983 & 1.085 & 1.102 & 0.98 \\
\hline Model 37 & 1.054 & 1.239 & 1.303 & 1.279 & 0.971 & 1.053 & 1.054 & 1.231 & 1.231 & 1.152 & 1.274 & 0.969 & 0.952 & 1.052 & 1.148 \\
\hline Model 38 & 1.293 & 1.368 & 1.308 & 1.259 & 1.188 & 1.182 & 1.045 & 1.204 & 1.206 & 1.19 & 1.073 & 0.99 & 1.016 & 1.127 & 0.954 \\
\hline Model 39 & 1.41 & 1.424 & 1.473 & 1.449 & 1.21 & 1.338 & 1.251 & 1.288 & 1.325 & 1.378 & 1.14 & & 1.226 & 1.244 & 1.08 \\
\hline Model 40 & 1.309 & 1.396 & 1.508 & 1.509 & 1.143 & 1.291 & 1.278 & 1.297 & 1.328 & 1.455 & 1.109 & 1.112 & 1.264 & 1.251 & 1.084 \\
\hline Model 41 & 1.114 & 1.299 & 1.269 & 1.248 & 1.05 & 1.078 & 1.044 & 1.186 & 1.194 & 1.173 & 1.005 & 0.99 & 1.016 & 1.107 & 0.954 \\
\hline Model 42 & 1.024 & 1.028 & 1.125 & 1.154 & 0.919 & 1.012 & 1.021 & 0.998 & 1.017 & 1.122 & 0.905 & 0.915 & 1.006 & 0.993 & 0.903 \\
\hline Model 43 & 1.469 & 1.702 & 2.086 & 1.917 & 1.208 & 1.454 & 1.441 & 1.7 & 1.437 & 1.899 & 1.203 & 1.122 & 1.424 & 1.434 & 1.117 \\
\hline
\end{tabular}


744 Table 5 The RRMSE of the coupled models

\begin{tabular}{|c|c|c|c|c|c|c|c|c|c|c|c|c|c|c|c|}
\hline $\begin{array}{c}\text { Empirical } \\
\text { model }\end{array}$ & RS1 & $\mathrm{RS} 2$ & RS3 & RS4 & R5 & RS6 & RS7 & RS8 & RS9 & RS10 & RS11 & RS12 & RS13 & RS14 & RS15 \\
\hline Model 1 & $10.99 \%$ & $10.02 \%$ & $11.20 \%$ & $10.55 \%$ & $9.76 \%$ & $11.00 \%$ & $10.17 \%$ & $10.03 \%$ & $9.46 \%$ & $10.41 \%$ & $9.77 \%$ & $9.01 \%$ & $10.03 \%$ & $41 \%$ & $.97 \%$ \\
\hline Model 2 & $10.98 \%$ & $9.94 \%$ & $11.20 \%$ & $10.53 \%$ & $.60 \%$ & $10.99 \%$ & $10.18 \%$ & $9.95 \%$ & $9.44 \%$ & $0.38 \%$ & $9.61 \%$ & $.94 \%$ & $0.03 \%$ & $40 \%$ & $.91 \%$ \\
\hline Model 3 & $10.96 \%$ & $9.96 \%$ & $11.19 \%$ & $10.55 \%$ & $9.64 \%$ & $10.98 \%$ & $10.18 \%$ & $9.97 \%$ & $9.45 \%$ & $10.39 \%$ & $9.65 \%$ & $8.96 \%$ & $10.03 \%$ & $9.41 \%$ & $8.94 \%$ \\
\hline Model 4 & $10.98 \%$ & $9.94 \%$ & $11.20 \%$ & $10.54 \%$ & $9.60 \%$ & $10.99 \%$ & $10.18 \%$ & $9.95 \%$ & $9.44 \%$ & $10.38 \%$ & $9.60 \%$ & $8.94 \%$ & $10.03 \%$ & $9.40 \%$ & $8.91 \%$ \\
\hline Model 5 & $10.96 \%$ & $9.91 \%$ & $11.18 \%$ & $10.54 \%$ & $9.57 \%$ & $10.98 \%$ & $10.18 \%$ & $9.91 \%$ & $9.43 \%$ & $10.38 \%$ & $9.57 \%$ & $8.94 \%$ & $10.03 \%$ & $9.40 \%$ & $8.91 \%$ \\
\hline Model 7 & $10.05 \%$ & $9.10 \%$ & $10.21 \%$ & $10.41 \%$ & $8.62 \%$ & $9.85 \%$ & $10.05 \%$ & $9.00 \%$ & $8.91 \%$ & $10.21 \%$ & $8.52 \%$ & $8.47 \%$ & $9.85 \%$ & $8.81 \%$ & $8.37 \%$ \\
\hline Model 8 & $9.87 \%$ & $8.91 \%$ & $10.08 \%$ & $10.18 \%$ & $8.45 \%$ & $9.73 \%$ & $9.86 \%$ & $8.85 \%$ & $8.65 \%$ & $10.06 \%$ & $8.39 \%$ & $8.27 \%$ & $9.74 \%$ & $4 \%$ & $8.25 \%$ \\
\hline Model 9 & $9.79 \%$ & $8.77 \%$ & $10.03 \%$ & $10.06 \%$ & & & & & & & & & & & $8.26 \%$ \\
\hline Model 10 & $10.90 \%$ & $9.79 \%$ & & $10.51 \%$ & $9.41 \%$ & $10.88 \%$ & & $9.79 \%$ & $9.45 \%$ & $10.39 \%$ & $9.41 \%$ & $8.97 \%$ & $10.03 \%$ & $9.40 \%$ & $8.92 \%$ \\
\hline Model 11 & $10.00 \%$ & $9.39 \%$ & $10.39 \%$ & $10.42 \%$ & $8.87 \%$ & $9.93 \%$ & $9.98 \%$ & $9.38 \%$ & $9.36 \%$ & $10.31 \%$ & $8.85 \%$ & $8.83 \%$ & $9.86 \%$ & $9.33 \%$ & $8.80 \%$ \\
\hline Model 15 & $9.19 \%$ & $8.84 \%$ & $9.69 \%$ & $9.71 \%$ & $8.27 \%$ & $9.18 \%$ & $9.17 \%$ & $8.81 \%$ & $8.69 \%$ & $9.69 \%$ & $8.26 \%$ & $8.20 \%$ & $9.16 \%$ & $8.67 \%$ & $8.19 \%$ \\
\hline Model 16 & $10.40 \%$ & $9.54 \%$ & $10.51 \%$ & $9.66 \%$ & $9.33 \%$ & $10.31 \%$ & $9.16 \%$ & $9.45 \%$ & $8.95 \%$ & $9.65 \%$ & $9.23 \%$ & $8.47 \%$ & $9.15 \%$ & $8.93 \%$ & $8.46 \%$ \\
\hline Model 17 & $10.80 \%$ & $10.02 \%$ & $11.06 \%$ & $9.93 \%$ & $9.75 \%$ & $10.81 \%$ & $9.34 \%$ & $10.03 \%$ & $9.29 \%$ & $9.93 \%$ & $9.76 \%$ & $8.71 \%$ & $9.34 \%$ & $9.29 \%$ & $8.71 \%$ \\
\hline Model 18 & $10.74 \%$ & $9.93 \%$ & $11.03 \%$ & $9.93 \%$ & $9.57 \%$ & $10.74 \%$ & $9.29 \%$ & $9.93 \%$ & $9.25 \%$ & $9.92 \%$ & $9.54 \%$ & $8.57 \%$ & $9.29 \%$ & $9.25 \%$ & $8.57 \%$ \\
\hline Model 19 & $9.13 \%$ & $8.74 \%$ & $9.63 \%$ & $9.64 \%$ & $8.19 \%$ & $9.13 \%$ & $9.12 \%$ & $8.73 \%$ & $8.60 \%$ & $9.63 \%$ & $8.19 \%$ & $8.13 \%$ & $9.11 \%$ & $8.59 \%$ & $8.13 \%$ \\
\hline Model 20 & $9.89 \%$ & $9.01 \%$ & $10.05 \%$ & $10.16 \%$ & $8.55 \%$ & $9.74 \%$ & $9.88 \%$ & $8.93 \%$ & $8.76 \%$ & $10.03 \%$ & $8.47 \%$ & $8.37 \%$ & $9.74 \%$ & $8.71 \%$ & $8.31 \%$ \\
\hline Model 21 & $9.99 \%$ & $9.09 \%$ & $10.14 \%$ & $10.31 \%$ & $8.62 \%$ & $9.82 \%$ & $9.99 \%$ & $9.00 \%$ & $8.91 \%$ & $10.14 \%$ & $8.52 \%$ & $8.47 \%$ & $9.82 \%$ & $8.81 \%$ & $8.37 \%$ \\
\hline Model 22 & $9.19 \%$ & $8.84 \%$ & $9.68 \%$ & $9.70 \%$ & $8.24 \%$ & $9.18 \%$ & $9.17 \%$ & $8.81 \%$ & $8.69 \%$ & $9.68 \%$ & $8.23 \%$ & $8.18 \%$ & $9.16 \%$ & $8.67 \%$ & $8.17 \%$ \\
\hline
\end{tabular}


745 Table 5 The RRMSE of the coupled models (continued)

\begin{tabular}{|c|c|c|c|c|c|c|c|c|c|c|c|c|c|c|c|}
\hline $\begin{array}{c}\text { Empirical } \\
\text { model }\end{array}$ & RS1 & $\mathrm{S} 2$ & S3 & S4 & S5 & RS6 & S7 & S8 & RS9 & RS10 & RS11 & $\mathrm{S} 12$ & $\mathrm{RS} 13$ & RS14 & S15 \\
\hline Model 23 & $46 \%$ & $9.22 \%$ & $02 \%$ & $8 \%$ & 8 & $9.46 \%$ & $1 \%$ & $0 \%$ & $8 \%$ & $\%$ & $\%$ & $6 \%$ & $\%$ & $\%$ & $45 \%$ \\
\hline Mo & $9.12 \%$ & $8.75 \%$ & $9.60 \%$ & $9.60 \%$ & $8.22 \%$ & $9.12 \%$ & $.11 \%$ & $.74 \%$ & $59 \%$ & $9.60 \%$ & $.22 \%$ & $4 \%$ & $9.11 \%$ & $58 \%$ & $14 \%$ \\
\hline 25 & $12 \%$ & 8 & 9 & $9.59 \%$ & 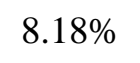 & $\%$ & 2 & 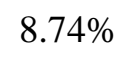 & $8.58 \%$ & $9.59 \%$ & $\%$ & $\%$ & $\%$ & $\%$ & $0 \%$ \\
\hline Mod & $3.97 \%$ & $4.11 \%$ & $15.01 \%$ & $15.08 \%$ & $12.14 \%$ & $.32 \%$ & $12.67 \%$ & $12.85 \%$ & $.33 \%$ & $14.59 \%$ & $.30 \%$ & $\%$ & $\%$ & $.64 \%$ & $.75 \%$ \\
\hline $\mathrm{M}$ & $.98 \%$ & $15.79 \%$ & $08 \%$ & $\%$ & $\%$ & $\%$ & $\%$ & $\%$ & $\%$ & $\%$ & $\%$ & $\%$ & & $\%$ & $\%$ \\
\hline 28 & $4.57 \%$ & 0.0710 & $20.68 \%$ & $19.00 \%$ & $11.97 \%$ & $1.42 \%$ & ats & $16.85 \%$ & $4.25 \%$ & (2) & $11.93 \%$ & $11.12 \%$ & $14.12 \%$ & - & 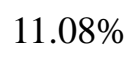 \\
\hline 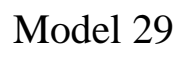 & $.42 \%$ & (5) & $75 \%$ & 年 & $\%$ & $2 \%$ & 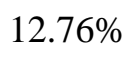 & $\%$ & $8 \%$ & $15.15 \%$ & $11.06 \%$ & $\%$ & $\%$ & $\%$ & $10.01 \%$ \\
\hline Model 30 & $13.95 \%$ & $13.79 \%$ & $14.32 \%$ & $13.92 \%$ & $12.17 \%$ & $3.30 \%$ & $12.69 \%$ & $12.63 \%$ & $12.88 \%$ & $13.67 \%$ & $11.31 \%$ & $11.08 \%$ & $12.54 \%$ & $12.34 \%$ & $10.79 \%$ \\
\hline Model 31 & $13.81 \%$ & $13.50 \%$ & $14.22 \%$ & $13.67 \%$ & $12.11 \%$ & $13.18 \%$ & $12.30 \%$ & $12.39 \%$ & $12.31 \%$ & $13.43 \%$ & $11.27 \%$ & $10.84 \%$ & $12.20 \%$ & $11.89 \%$ & $10.61 \%$ \\
\hline 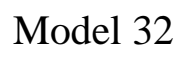 & tes & & & & & & & & & & & & & & - \\
\hline W & $.12 \%$ & $.02 \%$ & $.69 \%$ & 0070 & $10.21 \%$ & $\%$ & $12.11 \%$ & $\%$ & $11.45 \%$ & 15 & 10 & 10 & 12 & 10 & .0170 \\
\hline Model 34 & $11.72 \%$ & $11.67 \%$ & $12.72 \%$ & $12.94 \%$ & $10.14 \%$ & $11.63 \%$ & $11.71 \%$ & $11.30 \%$ & $11.19 \%$ & $12.68 \%$ & $10.02 \%$ & $9.86 \%$ & $2 \%$ & $10.95 \%$ & $9.80 \%$ \\
\hline Model 35 & $13.82 \%$ & $16.85 \%$ & $19.18 \%$ & $16.34 \%$ & $11.96 \%$ & $13.42 \%$ & $12.92 \%$ & $16.84 \%$ & $14.08 \%$ & $15.49 \%$ & $11.93 \%$ & $11.08 \%$ & $12.27 \%$ & $13.91 \%$ & $10.96 \%$ \\
\hline G 126 & 26207 & 46207 & $5.600 t+2$ & $12.14 \%$ & $11.08 \%$ & $12.24 \%$ & & & & & & & 10.7 & & $.72 \%$ \\
\hline ivious & $10.45 \%$ & $12.28 \%$ & $12.92 \%$ & $12.68 \%$ & 9.6 & $10.44 \%$ & $10.45 \%$ & $12.20 \%$ & $12.20 \%$ & 11.4270 & $12.63 \%$ & 9.0070 & $9.44 \%$ & $10.43 \%$ & $11.38 \%$ \\
\hline Model 38 & $12.82 \%$ & $13.56 \%$ & $12.97 \%$ & $12.48 \%$ & $11.78 \%$ & $11.71 \%$ & $10.36 \%$ & $11.93 \%$ & $11.96 \%$ & $11.80 \%$ & $10.64 \%$ & $9.82 \%$ & $10.07 \%$ & $11.17 \%$ & $9.46 \%$ \\
\hline Mod & $13.98 \%$ & $14.11 \%$ & $14.61 \%$ & $14.37 \%$ & $11.99 \%$ & $13.27 \%$ & $12.40 \%$ & $12.77 \%$ & $13.13 \%$ & $13.67 \%$ & $11.30 \%$ & $11.01 \%$ & $12.15 \%$ & $12.33 \%$ & $10.70 \%$ \\
\hline Model 40 & $12.97 \%$ & $13.84 \%$ & $4.95 \%$ & $14.96 \%$ & $11.33 \%$ & $12.80 \%$ & $2.67 \%$ & $12.86 \%$ & $13.16 \%$ & 14420 & $10.99 \%$ & $11.02 \%$ & $12.53 \%$ & $12.40 \%$ & $10.75 \%$ \\
\hline Model 41 & $11.04 \%$ & $12.88 \%$ & $12.59 \%$ & $12.37 \%$ & $10.41 \%$ & $10.69 \%$ & $10.35 \%$ & $11.76 \%$ & $11.84 \%$ & $11.63 \%$ & $9.96 \%$ & $9.82 \%$ & $10.07 \%$ & $10.98 \%$ & $9.46 \%$ \\
\hline Model 42 & $10.15 \%$ & $10.19 \%$ & $11.16 \%$ & $11.44 \%$ & $9.11 \%$ & $10.04 \%$ & $10.12 \%$ & $9.89 \%$ & $10.08 \%$ & $11.12 \%$ & 8.9 & $7 \%$ & 9.9 & $9.84 \%$ & $8.95 \%$ \\
\hline Model 43 & $10.16 \%$ & $1.00 \%$ & $.48 \%$ & $11.83 \%$ & $5 \%$ & $10.05 \%$ & $10.14 \%$ & $10.60 \%$ & $10.80 \%$ & 11. & $9.11 \%$ & $\%$ & $\%$ & $10.50 \%$ & 9.09 \\
\hline
\end{tabular}



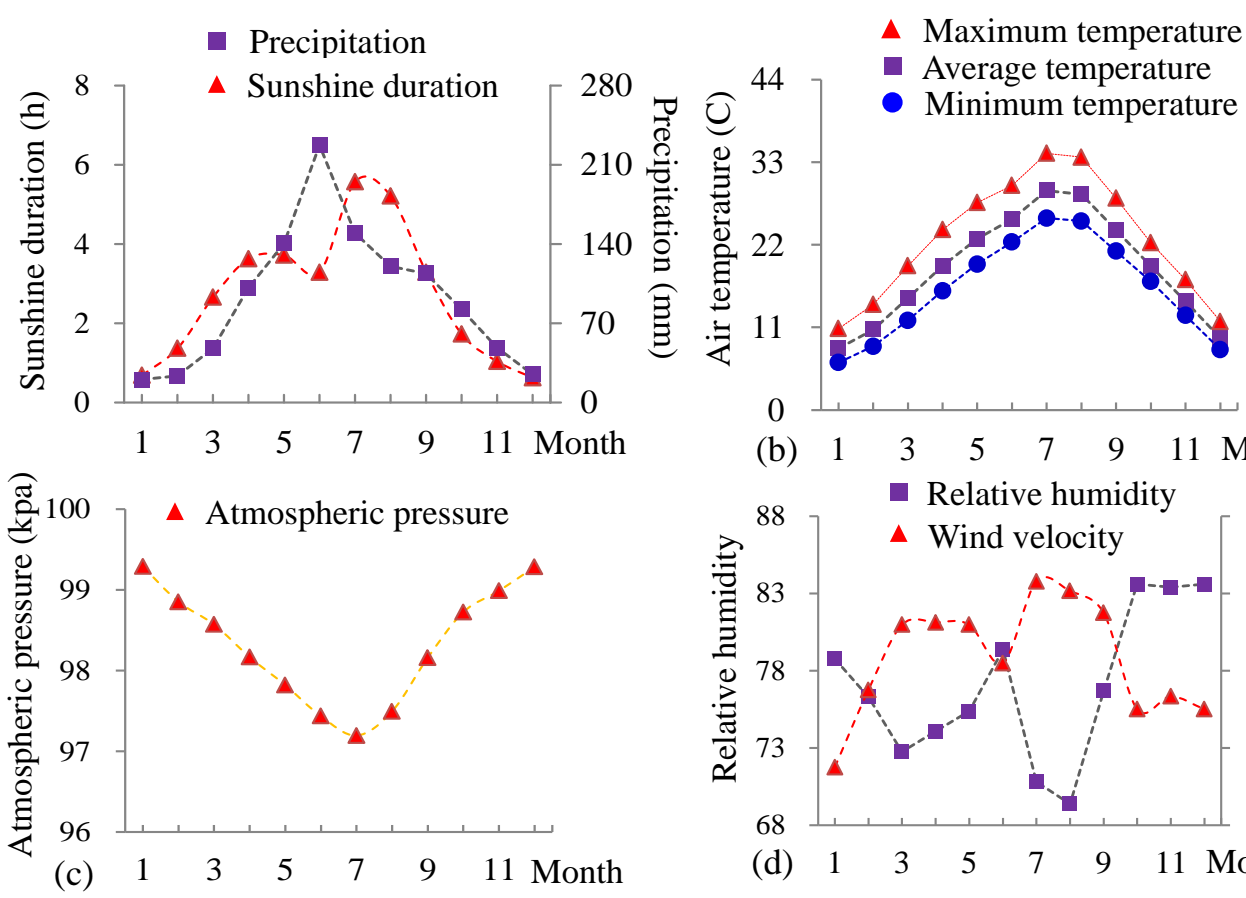

(b) $\begin{array}{lllllll}1 & 3 & 5 & 7 & 9 & 11 & \text { Month }\end{array}$

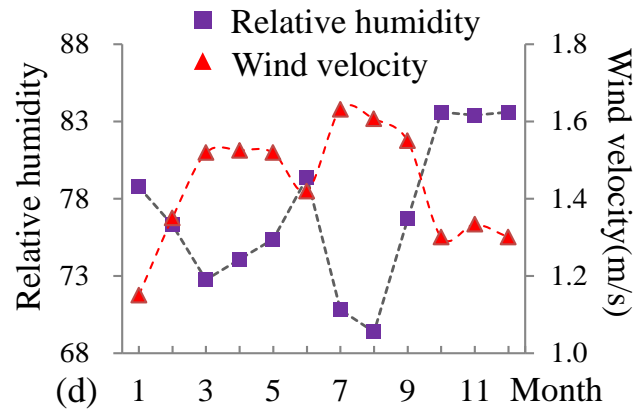

Figure.1 Temporal variations of the meteorological variables in Chongqing, China 